\title{
Thermal care of newborns: drying and bathing practices in Malawi and Bangladesh
}

\author{
Shane M Khan ${ }^{1}$, Eunsoo Timothy \\ Kim $^{2,3}$, Kavita Singh ${ }^{2,3}$, Agbessi \\ Amouzou $^{4}$, Liliana Carvajal- \\ Aguirre $^{1}$ \\ ${ }^{1}$ Data and Analytics, Division of Data, \\ Research and Policy, United Nations \\ Children's Fund (UNICEF), New York, New \\ York, USA \\ 2 Department of Maternal and Child Health, \\ Gillings School of Global Public Health, \\ University of North Carolina at Chapel Hill, \\ Chapel Hill, North Carolina, USA \\ ${ }^{3}$ Carolina Population Center, University of \\ North Carolina at Chapel Hill, Chapel Hill, \\ North Carolina, USA \\ 4 Johns Hopkins Bloomberg School of Public \\ Health, Baltimore, Maryland, USA
}

Background Thermal care of newborns is one of the recommended
strategies to reduce hypothermia, which contributes to neonatal mor-
bidity and mortality. However, data on these two topics have not been collected at the national level in many surveys. In this study, we examine two elements of thermal care: drying and delayed bathing of newborns after birth with the objectives of examining how two countries collected such data and then looking at various associations of these outcomes with key characteristics. Further, we examine the data for potential data quality issues as this is one of the first times that such data are available at the national level.

Methods We use data from two nationally-representative household surveys: the Malawi Multiple Indicator Cluster Survey 2014 and the Bangladesh Demographic and Health Survey 2014. We conduct descriptive analysis of the prevalence of these two newborn practices by various socio-demographic, economic and health indicators.

Results Our results indicate high levels of immediate drying/drying within 1 hour in Malawi (87\%). In Bangladesh, 84\% were dried within the first 10 minutes of birth. Bathing practices varied in the two settings; in Malawi, only 26\% were bathed after 24 hours but in Bangladesh, $87 \%$ were bathed after the same period. While in Bangladesh there were few newborns who were never bathed (less than 5\%), in Malawi, over 10\% were never bathed. Newborns delivered by a skilled provider tended to have better thermal care than those delivered by unskilled providers.

Conclusion These findings reveal gaps in coverage of thermal care and indicate the need to further develop the role of unskilled providers who can give unspecialized care as a means to improve thermal care for newborns. Further work to harmonize data collection methods on these topics is needed to ensure comparable data across countries.

\section{Correspondence to:}

Shane M. Khan

Data and Analytics, Data, Research and Policy United Nations Children's Fund (UNICEF)

3 United Nations Plaza

New York, NY 10017

USA

smkhan@unicef.org 
The "Every Newborn Action Plan" which is supported by the World Health Organization (WHO) and the United Nations Children's Fund (UNICEF) and various other institutions emphasizes the critical period of labour, birth and the first week of life as a period that can be targeted to prevent newborn deaths [4]. An important set of interventions designed to minimize preventable deaths during this critical period is essential newborn care (ENC), which broadly includes hygienic cord care, thermal protection and early initiation of breastfeeding [4]. Thermal protection and care of newborns is recommended as it reduces hypothermia, a condition in which the body temperature falls below normal levels [5] and which is known to contribute to global neonatal mortality either directly or indirectly as a comorbidity of other major causes of death [6]. A recent systematic review of low- and middle-income countries found that the prevalence of hypothermia ranged between 32\% and 85\% for newborns delivered at hospitals and between $11 \%$ and $92 \%$ for newborns delivered at homes [6]. The review suggests that the wide-ranging prevalence of hypothermia may be associated with different risk factors including low environmental temperatures, early bathing, low socioeconomic status of the mother/family and newborn complications such as low birth weight, prematurity, intrauterine growth restriction and birth asphyxia [6].

Key interventions to prevent newborn hypothermia and its associated mortality risk are described as a chain of interlinked operations. The WHO practical guide for thermal protection of newborns recommends several key interventions to ensure that the newborn is kept warm. This includes that the place of delivery is warm, newborns are immediately dried and either wrapped or placed on the mother for skinto-skin contact. The recommendation also states that bathing should be delayed for at least 24 hours following birth, or six hours, if culturally appropriate, and that breastfeeding is initiated within one hour after delivery [5].

A 2013 WHO recommendation on postnatal thermal care for newborns refers to the timing of first bath and echoes the same recommendation the timing of bathing [7]. The integrated management of pregnancy and childbirth provides similar advice on drying and placing the baby on the mother's chest with skinto-skin contact right after birth [8]. In addition, the recently released "Standards for improving quality of maternal and newborn care in health facilities" [9] includes immediate and thorough drying of the newborn as a quality measure. Drying and rubbing are also an essential step in newborn resuscitation used with newborns who do not breathe spontaneously after birth [9].

Several studies in the past have examined the use of protective thermal care practices for newborns. Many have found that there is low use of adequate thermal care practices across South Asia and sub-Saharan Africa. For example, Pagel et al. reports that newborn wrapping or skin-to-skin contact within 10 minutes was relatively low for both home and facility deliveries in Eastern India and Bangladesh [10]. Coverage of bathing after 6 hours, varied widely by study location and delivery types [10]. Another study in Bangladesh reports that only $5.1 \%$ of newborns received complete thermal protection, defined as drying and wrapping within 10 minutes and bathing after 72 hours of birth [11]. A study in western Uganda had higher proportions of wrapping the newborn (85.1\%) and delaying bathing until after 24 hours (66.3\%) [12]. Key findings from qualitative and mixed-method studies have also shown that newborn bathing practices varied across studies but were mostly favouring early bathing due to strong cultural and traditional beliefs [13-16].

Among the recommended thermal care practices, there are few countries with national data on the topics. However, two recent national surveys in Malawi and Bangladesh have included new questions on newborn drying and bathing. There are two primary objectives of this study. The first is to describe the approaches used to collect data on these topics and then to describe associations between these two thermal care practices and key variables. As this is one of the first time that these data are being examined at the national level in the Malawi Multiple Indicator Cluster Survey (MICS) 2014 and the Bangladesh Demographic and Health Survey (DHS) 2014, we also examine potential data quality issues which can inform the development of future data collection on drying and bathing using household surveys.

\section{METHODS}

\section{Data source}

We searched the UNICEF-supported Multiple Indicator Cluster Surveys (MICS) and the USAID-supported Demographic and Health Surveys (DHS) for data on newborn drying and bathing. Data were available from the Malawi MICS 2014 and the Bangladesh DHS 2014. The surveys used a similar two-stage sam- 
pling methodology, where census enumeration areas were first selected and then households were selected in the second stage. In the households, all women age 15-49 were interviewed in Malawi while in Bangladesh, only ever-married women were interviewed. In the Malawi MICS 2014, questions on drying and bathing were asked about the last birth in the last 2 years, while in Bangladesh, questions were asked about the last birth in the last 3 years. The sample sizes were 7490 in Malawi and 4626 in Bangladesh.

\section{Questions on drying}

The Malawi MICS 2014 asked "Was (name) dried or wiped after delivery?" The question provided response categories of 'yes', 'no', 'don't know' and 'missing' and among those who said yes, "How soon after birth was (name) dried or wiped?" recording the time in hours, with additional categories for immediate drying/less than 1 hour and another category for don't know/don't remember.

The Bangladesh DHS 2014 asked one question on drying, "How long after birth was (NAME) dried?" providing categorical response categories of $<5$ minutes, 5-9 minutes, $10+$ minutes, not dried, and don't know.

\section{Questions on bathing}

The question on bathing in the Malawi MICS 2014 was, "How soon after birth was (name) bathed for the first time?" recording the time in hours, with additional categories for immediate bathing (less than an hour), never bathed and don't know/don't remember. It should be noted that in this survey, newborns who were not dried were skipped out of the question on bathing.

The Bangladesh DHS 2014 asked, "How long after delivery was (NAME) bathed for the first time?" recording the time in hours (if less than 1 day), days (if less than 1 week), weeks, not bathed, and don't know.

\section{Variables and analysis}

As the aim of this analysis is to understand patterns of drying and bathing across the two countries, the analysis is descriptive. Questions on drying are not comparable across the two surveys and do not allow the calculation of a comparable 'immediate drying' variable. Therefore, in both data sets, we dichotomized the variable as 'dried' or 'not dried' without regard for the timing of drying. Missing and don't know cases were minimal and treated as "not bathed" in Table 1 and Table 2.

For the bathing variables, we created a variable to measure bathing after 24 hours. These data were only collected in hours in the Malawi MICS 2014, and were categorized according to the definition of above 24 hours, less than 24 hours, and cases of never bathed, don't know or missing were coded as missing for the tables. For the Bangladesh DHS 2014, we coded bathing at day 1 as bathing after 24 hours (as values over 24 hours were collected in days), coding not bathed, don't know and missing as missing values for the tables. We stratified the analysis by facility vs non-facility births given that the recommendations on thermal care can theoretically differ across these strata. In both surveys, facility births included hospitals, clinics and health centres while non-facility births were all other locations.

In the analysis, we used a number of background variables to examine drying and bathing. Mother's age in years was categorized as less than 20,20 to 34 and 35 to 49. Birth order referred to the order of the birth of the newborn, categorized as 1 which refers to the first birth, 2-3 (the second and third births), 4-5 (fourth and fifth births) and 6+ which referred to sixth and higher order births. Mother's education was categorized as no education, primary, and a third category of secondary and higher (including university). Size of birth is based on the mother's perception of how large or small the newborn was (at birth). Attendant at delivery was categorized as either skilled or unskilled. Skilled in Malawi referred to births delivered by a doctor or nurse/midwife while skilled in Bangladesh referred to births delivered by a qualified doctor, nurse/midwife/paramedic while unskilled referred to the residual categories in each country. C-section referred to Caesarean section for delivery of the newborn. Residence referred to the type of location where the woman lived and was categorized as urban or rural. The wealth variable was calculated using Principal Component Analysis (PCA). The PCA assigned overall scores to households based on household ownership of goods and assets. The PCA ranked households and then categorized them into five categories: poorest, second, middle, fourth and richest households. Antenatal care referred to the number of times a woman visited any provider during the pregnancy of the newborn for antenatal care. This variable was categorized into no visits (labelled "none"), 2, 3 and 4 or more visits (labelled "4+").

Sampling weights supplied with the data sets were used in all analyses. 


\section{RESULTS}

Figure 1 and Figure 2 present the distribution of newborn drying in the two countries. An overwhelming majority of women $(87 \%)$ said that their newborns were dried immediately or within 1 hour in Malawi. In Bangladesh, $68 \%$ of women said that their newborns were dried within 5 minutes of birth, 16\% within 5-9 minutes following birth and 7\%, 10 minutes or later. The percentage of newborns not dried was 5 and 6 percent in Malawi and Bangladesh respectively.

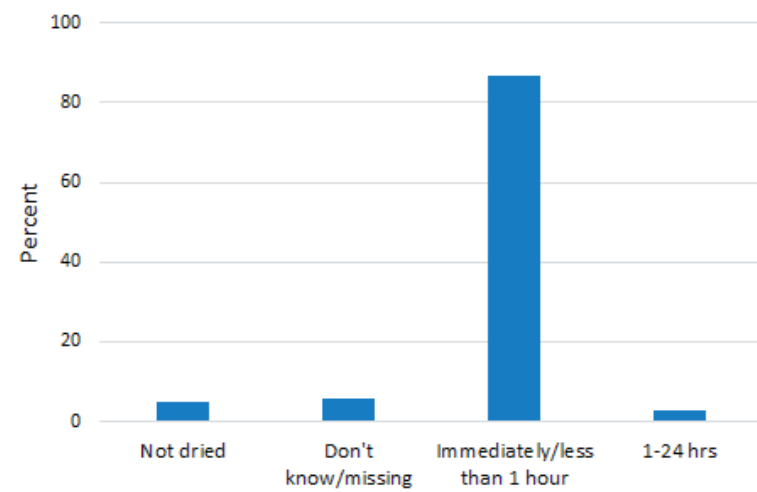

Figure 1. Newborn drying in Malawi.

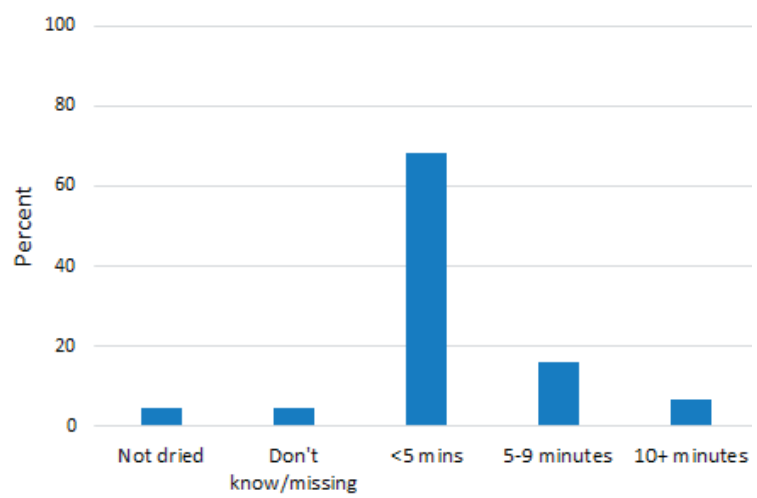

Figure 2. Newborn drying in Bangladesh.

Table 1 and Table 2 show distributions of drying of the newborn in each country and how they vary by facility and key variables. About $90 \%$ of newborns were dried in both countries. With such high coverage, differentials across socio-demographic subgroups were generally weak. However, several variables showed notable differences. While newborns who were born in a facility in Malawi were significantly more likely to be dried compared to those born outside a facility (93\% vs 84\%), in Bangladesh, there is no discernible difference. Likewise, in Malawi, births with a skilled provider were more likely to be dried (95\%) compared to those with an unskilled provider (78\%) though this pattern was not found in Bangladesh. Women who had had no antenatal visits were least likely to have a newborn that was dried (53\%) compared to others with such care (1 or more visits, $>90 \%$ ) in Malawi. This differential was significant in Bangladesh as well but differences in levels were not substantial. In both countries, women who had a C-section reported less drying than women with vaginal births (eg, in Bangladesh, $87 \%$ vs 92\%). In addition, in Malawi, place of residence was also a marker for differences in drying with a larger proportion of mothers in rural areas reporting that the baby was dried immediately after birth. In Bangladesh, mother's education and household wealth also show significant differences in the results regarding newborn drying with mothers with no education and in the poorest households reporting lower levels of newborn drying. Despite significance, differences are not substantial.

Table 1. Percentage of newborns which were dried in Malawi, by place of delivery and various characteristics

\begin{tabular}{|c|c|c|c|c|c|c|}
\hline \multicolumn{7}{|c|}{ Place of delivery } \\
\hline & Facility & $\mathrm{N}$ & Non-facility & $\mathrm{N}$ & Total & $\mathrm{N}$ \\
\hline \multicolumn{7}{|l|}{ Mother's age (years): } \\
\hline$<20$ & 91.3 & 947 & 93.4 & 55 & 91.4 & 1002 \\
\hline $20-34$ & 93.5 & 4962 & 81.8 & 413 & 92.6 & 5375 \\
\hline $35-49$ & 91.3 & 968 & 86.5 & 145 & 90.7 & 1113 \\
\hline \multicolumn{7}{|l|}{ Birth order: } \\
\hline 1 & 94.2 & 152 & 94.9 & 16 & 94.3 & 168 \\
\hline $2-3$ & 91.2 & 553 & 82.7 & 57 & 90.4 & 610 \\
\hline $4-5$ & 92.9 & 1489 & 87.5 & 116 & 92.5 & 1605 \\
\hline $6+$ & 93.1 & 4683 & 82.7 & 424 & 92.2 & 5107 \\
\hline \multicolumn{7}{|l|}{ Mother's education: } \\
\hline No education & 92.3 & 743 & 77.2 & 129 & 90.1 & 872 \\
\hline Primary education & 93.0 & 4866 & 85.5 & 453 & 92.3 & 5318 \\
\hline Secondary or higher & 92.9 & 1268 & 89.3 & 32 & 92.8 & 1300 \\
\hline Size at birth: & $\neq$ & & & & & \\
\hline Very small & 92.7 & 431 & 61.8 & 61 & 75.2 & 492 \\
\hline Smaller than average & 93.9 & 584 & 84.9 & 66 & 93.0 & 650 \\
\hline
\end{tabular}


Table 1. Continued

\begin{tabular}{|c|c|c|c|c|c|c|}
\hline \multicolumn{7}{|c|}{ Place of delivery } \\
\hline & Facility & $\mathrm{N}$ & Non-facility & $\mathrm{N}$ & Total & $\mathbf{N}$ \\
\hline Average & 94.6 & 3495 & 85.0 & 325 & 93.8 & 3820 \\
\hline Larger than average & 93.2 & 1684 & 84.5 & 111 & 92.7 & 1795 \\
\hline Very large & 93.6 & 683 & 87.5 & 50 & 93.2 & 733 \\
\hline Attendant at delivery: & † & & & & 丰 & \\
\hline Skilled & 94.5 & 6383 & 100.0 & 610 & 94.5 & 6386 \\
\hline Unskilled provider & 71.6 & 494 & 90.1 & 3 & 78.4 & 1104 \\
\hline C-section: & $\neq$ & & & & 丰 & \\
\hline No & 93.6 & 6482 & 84.0 & 515 & 92.8 & 7095 \\
\hline Yes & 81.3 & 396 & 0.0 & 0 & 81.3 & 396 \\
\hline Residence: & $\dagger$ & & $\neq$ & & $\neq$ & \\
\hline Urban & 88.8 & 860 & 45.6 & 29 & 87.4 & 889 \\
\hline Rural & 93.5 & 6018 & 85.9 & 584 & 92.8 & 6602 \\
\hline Wealth: & & & $\ddagger$ & & & \\
\hline Poorest & 93.2 & 1615 & 88.3 & 237 & 92.5 & 1853 \\
\hline Second & 94.5 & 1522 & 87.5 & 153 & 93.8 & 1676 \\
\hline Middle & 92.7 & 1425 & 82.0 & 132 & 91.8 & 1556 \\
\hline Fourth & 92.3 & 1176 & 72.5 & 67 & 91.2 & 1242 \\
\hline Richest & 91.2 & 1139 & 61.7 & 24 & 90.6 & 1163 \\
\hline Antenatal visits: & $\ddagger$ & & & & † & \\
\hline None & 43.9 & 169 & 75.6 & 68 & 53.3 & 237 \\
\hline 1 & 95.8 & 133 & 83.7 & 41 & 92.9 & 174 \\
\hline 2 & 94.5 & 755 & 84.7 & 121 & 93.1 & 877 \\
\hline 3 & 93.1 & 2650 & 84.1 & 202 & 92.4 & 2852 \\
\hline $4+$ & 94.8 & 3170 & 86.2 & 181 & 94.4 & 3351 \\
\hline Total & 92.9 & 6877 & 84.0 & 613 & 92.2 & 7490 \\
\hline
\end{tabular}

Table 2. Percentage of newborns which were dried in Bangladesh, by place of delivery and various characteristics

\begin{tabular}{|c|c|c|c|c|c|c|}
\hline \multicolumn{7}{|c|}{ Place of delivery } \\
\hline & Facility & $\mathbf{N}$ & Non-facility & $\mathrm{N}$ & Total & $\mathrm{N}$ \\
\hline \multicolumn{7}{|l|}{ Mother's age (years): } \\
\hline$<20$ & 89.7 & 351 & 93.1 & 619 & 91.8 & 970 \\
\hline $20-34$ & 89.9 & 1334 & 92.1 & 2043 & 91.2 & 3379 \\
\hline $35-49$ & 82.4 & 100 & 84.1 & 178 & 83.5 & 277 \\
\hline Birth order: & & & $\dagger$ & & $*$ & \\
\hline 1 & 89.0 & 888 & 93.8 & 956 & 91.4 & 1845 \\
\hline $2-3$ & 90.4 & 786 & 91.3 & 1355 & 91.0 & 2141 \\
\hline $4-5$ & 87.7 & 96 & 93.2 & 388 & 92.1 & 484 \\
\hline $6+$ & 77.5 & 14 & 79.0 & 141 & 78.8 & 155 \\
\hline Mother's education: & & & $\dagger$ & & $*$ & \\
\hline No education & 85.7 & 283 & 89.1 & 1120 & 88.4 & 1403 \\
\hline Primary education & 89.8 & 955 & 93.1 & 1479 & 91.8 & 2436 \\
\hline Secondary or higher & 90.8 & 545 & 96.1 & 241 & 92.4 & 786 \\
\hline \multicolumn{7}{|l|}{ Size at birth: } \\
\hline Very small & 86.3 & 124 & 91.4 & 191 & 89.4 & 316 \\
\hline Smaller than average & 85.6 & 198 & 88.0 & 409 & 87.2 & 607 \\
\hline Average & 90.8 & 1193 & 92.4 & 1911 & 91.8 & 3105 \\
\hline Larger than average & 88.4 & 240 & 91.6 & 256 & 90.1 & 495 \\
\hline Very large & 82.2 & 29 & 97.4 & 73 & 93.1 & 102 \\
\hline \multicolumn{7}{|l|}{ Attendant at delivery: } \\
\hline Skilled & 89.3 & 1740 & 92.9 & 228 & 89.7 & 1970 \\
\hline Unskilled provider & 95.3 & 44 & 91.7 & 2612 & 91.8 & 2656 \\
\hline C-section: & & & & & $\dagger$ & \\
\hline No & 92.8 & 663 & 91.8 & 2840 & 92.0 & 3504 \\
\hline Yes & 87.5 & 1120 & 0.0 & 0 & 87.4 & 1121 \\
\hline \multicolumn{7}{|l|}{ Residence: } \\
\hline Urban & 91.3 & 705 & 93.1 & 504 & 92.0 & 1209 \\
\hline Rural & 88.3 & 1078 & 91.5 & 2337 & 90.5 & 3416 \\
\hline Wealth: & & & & $\dagger$ & $*$ & \\
\hline
\end{tabular}


Table 2. Continued

\begin{tabular}{|c|c|c|c|c|c|c|}
\hline \multicolumn{7}{|c|}{ Place of delivery } \\
\hline & Facility & $\mathrm{N}$ & Non-facility & $\mathrm{N}$ & Total & $\mathrm{N}$ \\
\hline Poorest & 79.8 & 154 & 89.3 & 849 & 87.8 & 1003 \\
\hline Second & 87.8 & 214 & 88.1 & 660 & 88.0 & 876 \\
\hline Middle & 88.0 & 307 & 94.2 & 574 & 92.0 & 881 \\
\hline Fourth & 90.8 & 455 & 95.8 & 500 & 93.4 & 955 \\
\hline Richest & 92.0 & 654 & 96.6 & 258 & 93.3 & 912 \\
\hline Antenatal visits: & & & * & & * & \\
\hline None & 87.6 & 110 & 88.3 & 886 & 88.2 & 996 \\
\hline 1 & 91.1 & 219 & 90.2 & 608 & 90.4 & 827 \\
\hline 2 & 92.5 & 313 & 93.8 & 435 & 93.2 & 748 \\
\hline 3 & 90.2 & 297 & 96.6 & 315 & 93.5 & 613 \\
\hline $4+$ & 87.9 & 845 & 94.7 & 595 & 90.7 & 1442 \\
\hline Total & 89.4 & 1784 & 91.8 & 2840 & 90.9 & 4626 \\
\hline
\end{tabular}

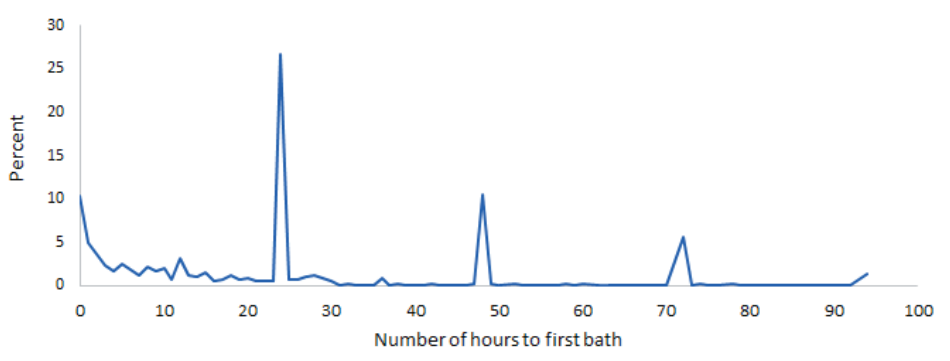

Figure 3. Bathing of newborns in Malawi in hours.

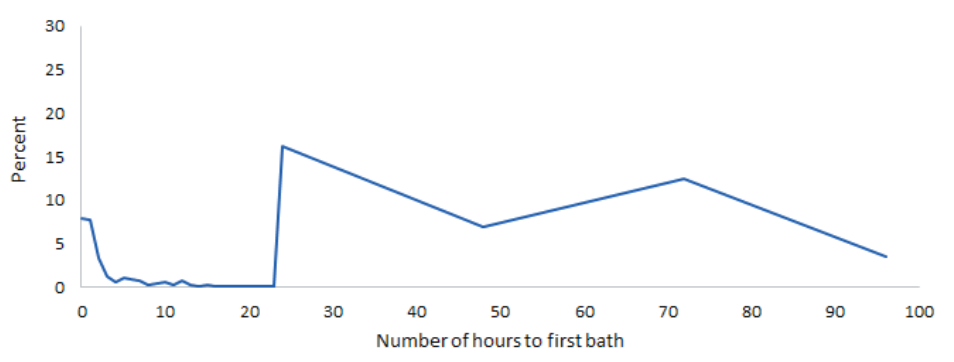

Figure 4. Bathing of newborns in Bangladesh in hours.
We examined the distribution of timing of bathing of newborns for the first 100 hours of life, shown in Figure 3 and Figure 4 (excluding cases where newborns were not bathed, about 10\% in Malawi and $5 \%$ in Bangladesh, or were missing). In both countries, there is a small but important percentage of newborns who are bathed immediately after birth (about 10\% in Malawi and 8\% in Bangladesh). The graphs also show clear evidence of heaping of the data. In Malawi, this is evident on hours 24, 48 and 72 which correspond to 1, 2 and 3 days. Similarly, in Bangladesh, some heaping occurs at 24 and 72 hours.

Table 3 and Table 4 show bathing after 24 hours in Malawi and Bangladesh. In these tables, cases of never bathed, don't know and missing were removed from analysis. In Malawi, only 26\% of newborns were bathed after 24 hours, while in Bangladesh, 74\% were bathed after 24 hours. In both countries, there were few missing cases (not included in the Tables 3 and 4). Comparing by place of birth, newborns in facilities were more likely to have a delayed bathed compared to those born outside of facilities in both countries (see Table 3 and 4). Newborns in Malawi and Bangladesh who were born using a skilled provider or those who were born with a C-section were more likely to have a delayed bath than those who were born to an unskilled provider or those born by a vaginal birth. For example, in Bangladesh, among all newborns, 92\% born using a skilled attendant was bathed after 24 hours while only $60 \%$ born without a skilled attendant was bathed after 24 hours.

\section{DISCUSSION}

Monitoring ENC is needed to identify programmatic coverage gaps and to provide an empirical basis for policy, accountability and investment to improve newborn survival and care. The renewed emphasis on newborn survival on the global agenda has led to the inclusion of new questions and modules on ENC in survey programs for the collection of data on key indicators in a systematic manner. For instance, in the latest round of MICS surveys, launched in late 2016, questions on ENC including thermal practices, cord care and skin-to-skin contact are included for countries to use. Changes have also occurred for the DHS surveys, which has an optional newborn care module with similar topics.

Levels of drying are remarkable similar in the two countries with nearly all newborns being dried. However, bathing practices differ in the two countries, with newborns in Malawi being bathed much earlier than those of Bangladesh. These levels seen in Malawi are much lower than those seen in Uganda in oth- 
Table 3. Bathing of newborns after $24 \mathrm{~h}$ in Malawi by place of delivery

\begin{tabular}{|c|c|c|c|c|c|c|}
\hline \multicolumn{7}{|c|}{ Place of delivery } \\
\hline & Facility & $\mathrm{N}$ & Non-facility & $\mathrm{N}$ & Total & $\mathbf{N}$ \\
\hline \multicolumn{7}{|l|}{ Mother's age (years): } \\
\hline$<20$ & 28.4 & 738 & 18.3 & 45 & 27.8 & 783 \\
\hline $20-34$ & 27.5 & 3925 & 13.5 & 299 & 26.5 & 4224 \\
\hline $35-49$ & 25.0 & 722 & 10.7 & 119 & 23.0 & 840 \\
\hline \multicolumn{7}{|l|}{ Birth order: } \\
\hline 1 & 21.8 & 118 & 0.0 & 13 & 19.7 & 131 \\
\hline $2-3$ & 22.2 & 438 & 7.4 & 39 & 21.0 & 477 \\
\hline $4-5$ & 29.4 & 1190 & 12.8 & 89 & 28.3 & 1279 \\
\hline $6+$ & 27.4 & 3638 & 14.6 & 322 & 26.4 & 3960 \\
\hline \multicolumn{7}{|l|}{ Mother's education: } \\
\hline No education & 26.7 & 550 & 20.3 & 83 & 25.9 & 634 \\
\hline Primary education & 27.8 & 3818 & 11.4 & 353 & 26.4 & 4171 \\
\hline Secondary or higher & 25.7 & 1016 & 15.8 & 26 & 25.4 & 1042 \\
\hline Size at birth: & & & & & $*$ & \\
\hline Very small & 34.8 & 253 & 6.2 & 43 & 30.7 & 296 \\
\hline Smaller than average & 35.4 & 441 & 18.1 & 53 & 33.6 & 494 \\
\hline Average & 25.2 & 2756 & 12.3 & 241 & 24.1 & 2997 \\
\hline Larger than average & 28.6 & 1393 & 16.8 & 85 & 27.9 & 1477 \\
\hline Very large & 24.8 & 542 & 12.2 & 42 & 23.9 & 583 \\
\hline Attendant at delivery: & & & & & $\neq$ & \\
\hline Skilled & 27.6 & 5075 & 0.0 & 3 & 27.6 & 5078 \\
\hline Unskilled provider & 22.7 & 309 & 13.3 & 459 & 17.1 & 769 \\
\hline C-section: & \# & & & & 韦 & \\
\hline No & 26.7 & 5131 & 0.0 & 0 & 25.6 & 5594 \\
\hline Yes & 40.4 & 254 & 13.2 & 462 & 40.4 & 254 \\
\hline \multicolumn{7}{|l|}{ Residence: } \\
\hline Urban & 24.1 & 662 & 0.0 & 11 & 23.7 & 674 \\
\hline Rural & 27.8 & 4722 & 13.6 & 451 & 26.5 & 5174 \\
\hline Wealth: & & & $\dagger$ & & & \\
\hline Poorest & 24.7 & 1252 & 13.5 & 190 & 23.3 & 1442 \\
\hline Second & 30.5 & 1197 & 7.0 & 119 & 28.4 & 1316 \\
\hline Middle & 28.8 & 1116 & 21.8 & 95 & 28.2 & 1211 \\
\hline Fourth & 25.9 & 938 & 5.5 & 44 & 25.0 & 982 \\
\hline Richest & 26.2 & 883 & 29.3 & 14 & 26.3 & 897 \\
\hline Antenatal visits: & & & $*$ & & & \\
\hline None & 26.9 & 43 & 5.8 & 47 & 15.8 & 90 \\
\hline 1 & 21.6 & 99 & 24.8 & 31 & 22.4 & 130 \\
\hline 2 & 29.4 & 597 & 12.0 & 89 & 27.1 & 686 \\
\hline 3 & 28.2 & 2094 & 17.2 & 150 & 27.4 & 2244 \\
\hline $4+$ & 26.3 & 2552 & 9.9 & 146 & 25.4 & 2697 \\
\hline Total & 27.3 & 5385 & 13.2 & 462 & 26.2 & 5847 \\
\hline
\end{tabular}

er literature [12]. The analysis also shows that skilled providers are important for the delivery of timely drying in both countries and drying in Malawi. However, given that a sizeable proportion of births occur outside of facility settings, it would be useful to ensure that unskilled providers are able to provider these two elements of thermal care. This recommendation is supported by the 2009 WHO/UNICEF joint statement on home visits for newborns, wherein both skilled and unskilled providers are endorsed for certain elements of care, including thermal care, following the time of birth [17].

Our results show that the measurement approaches used in these two surveys are not standardized. This is to be expected as these are initial efforts to measure these variables in the survey programmes. Drying data for the two surveys are largely incomparable. While the Malawi survey data allow a category of 'immediate drying', this category also includes cases of drying within 1 hour. The Bangladesh survey provides response categories using ranges of minutes and no 'immediate' drying category. As such, both cases do not allow an easy calculation of the 'immediate drying' indicator, which in part reflects the lack of 
Table 4. Bathing of newborns after $24 \mathrm{~h}$ in Bangladesh by place of delivery

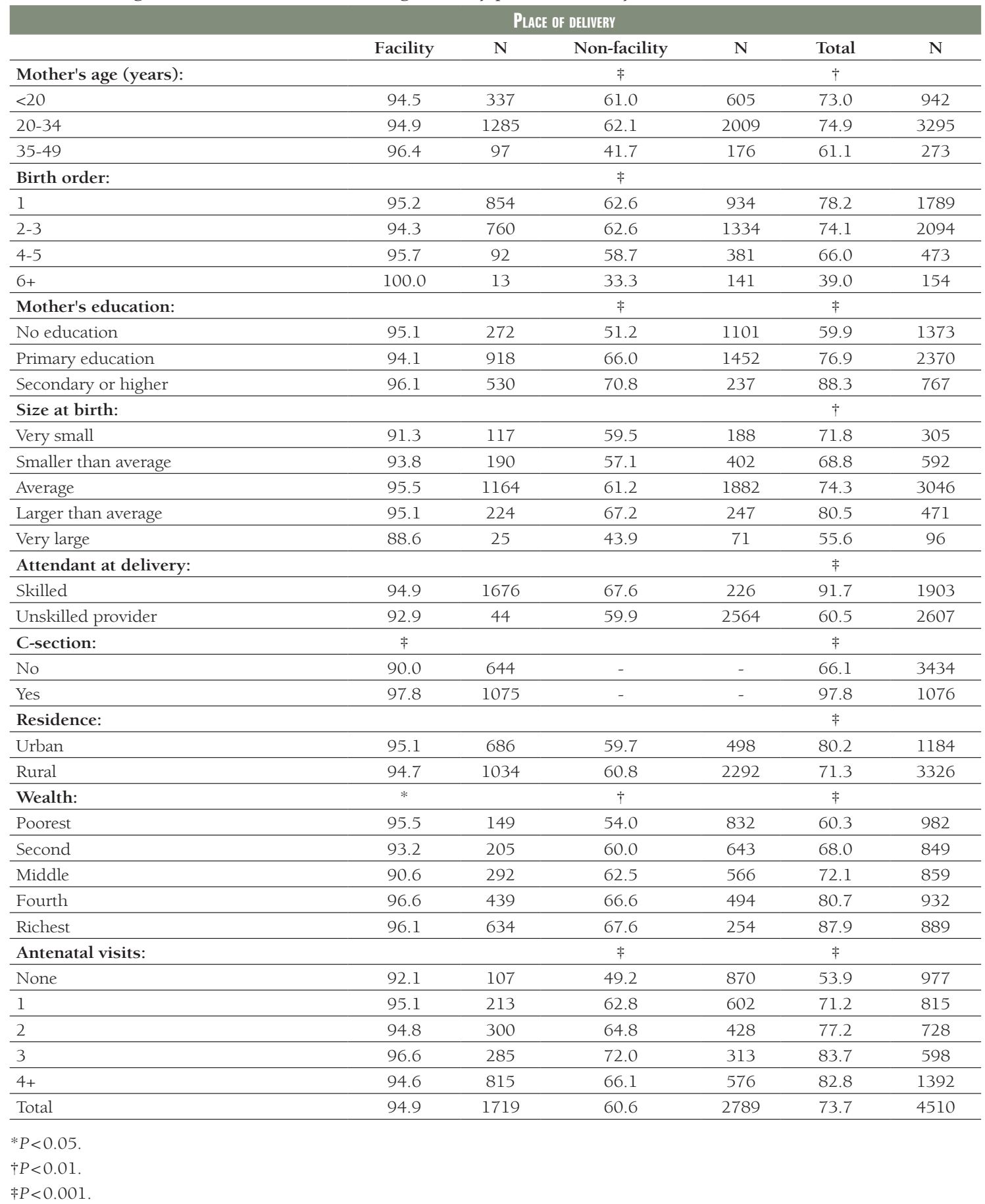

clarity of what constitutes 'immediate'. These concerns are largely addressed in the latest round of MICS and the DHS optional module on newborn care. In MICS6, the relevant question asks if the newborn was wiped or dried soon after birth, while the DHS asks if the newborn was wiped dry within a few minutes. It is of course necessary to note that both question approaches allow a certain level of subjectivity to measure the immediacy of drying, an approach that is necessary until there is an agreed definition of what 'immediate drying' refers to.

With reference to newborn bathing, the major methodological issue is that the cut-off for the indicator is for values greater than 24 hours. Both surveys show heaping of data at the 24-hour mark, which is used as a cut-off for indicator calculation. Similar heaping of data exists across different health and nutrition indicators such as low birth weight (at $2500 \mathrm{~g}$ ). Due to this issue, in the latest round of MICS, after the question on bathing is asked, an addition probe is activated if the respondent says that the newborn was bathed on the 1 day/24-hour mark to ascertain if the bath took place before, after or on that exact mo- 
ment. A similar approach can be useful for surveys using the DHS approach. We also detect that in Malawi an important proportion of cases was not bathed, but in Bangladesh, there were much fewer cases. It would be important to monitor this proportion in future surveys and to understand the circumstances that produce this outcome.

There are important limitations in this paper that should be considered when interpreting the results. Data on ENC practices used in the analysis are based on mother's recall of care provided to the newborn soon after birth. Apart from recall, women not know if certain events have occurred or the exact timing, especially in the case of C-sections, where the mother and newborn may be quickly separated. This may explain why women who had a C-section reported lower levels of drying. As with other measures based on mother's recall, this could have led to differential recall bias and may not entirely reflect the level of quality of care in facilities [18]. This is particularly the case for interventions that occur during the postpartum period as it is an intense moment for mothers. The Malawi MICS 2014, newborns who were not dried were skipped out of the question on bathing which can potentially under-estimate the indicator level, given that some newborns who are not dried could have a bath later than the 24-hour period. Due to the questions asked, a comparable measure of immediate drying could not be calculated. As such, the analysis in this paper focusses on newborns who were ever dried or not.

Our findings shed light into gaps on two essential yet simple newborn care interventions, which at low cost, can help maintain the newborn in a stable condition. The results also indicate potential areas of intervention for training up of staff for implementing drying and bathing in these countries. Further research is required to study the results of the new MICS and DHS approaches to measuring drying and bathing in different countries to ensure that the intention of these questions are properly reflected.

Disclaimer: The findings and conclusions in this report are those of the authors and do not necessarily represent the official position of their respective organizations.

Funding: None.

Authorship contributions: SMK led the development of the paper. SMK and ETK led the writing of the paper. ETK performed the data analysis. KS, AA and LCA provided substantial inputs and ideas into all drafts of the paper.

Competing interests: The authors has completed the Unified Competing Interest form at www.icmje.org/coi_ disclosure.pdf (available on request from the corresponding author) and declare no competing interests.

1 UNICEF. Committing to Child Survival: A Promise Renewed Progress Report 2015. Available: https://www.unicef.org/ publications/index_83078.html. Accessed: 1 October 2017.

2 Wardlaw T, You D, Hug L, Amouzou A, Newby H. UNICEF Report: enormous progress in child survival but greater focus on newborns urgently needed. Reprod Health. 2014;11:82. Medline:25480451 doi:10.1186/1742-4755-11-82

3 UNICEF. World Health Organization, World Bank, \& UN-DESA Population Division. Levels \&; Trends in Child Mortality 2015.

4 World Health Organization \& NICEF. EVERY NEWBORN: An Action Plan To End Preventable Deaths. 2014. Geneva. Available: http://apps.who.int/iris/bitstream/10665/127938/1/9789241507448_eng.pdf. Accessed: 1 October 2017.

5 World Health Organization. Maternal and Newborn Health/Safe Motherhood Unit. Thermal Protection of the Newborn: a practical guide. Geneva: World Health Organization; 1997.

6 Lunze K, Bloom DE, Jamison DT, Hamer DH. The global burden of neonatal hypothermia: systematic review of a major challenge for newborn survival. BMC Med. 2013;11:24. Medline:23369256 doi:10.1186/1741-7015-11-24

7 World Health Organization. Recommendations on Postnatal care of the mother and newborn. Available: http://apps. who.int/iris/bitstream/10665/97603/1/9789241506649_eng.pdf. Accessed: 1 April 2017.

8 World Health Organization. UNFPA, UNICEF. 2015. Integrated Management of Pregnancy and Childbirth. Pregnancy, childbirth, postpartum and newborn care: a guide for essential practice - 3rd edition. Available: http://apps.who.int/ iris/bitstream/10665/249580/1/9789241549356-eng.pdf. Accessed: 1 October 2017.

9 World Health Organization. Standards for improving quality of maternal and newborn care in health facilities. 2016. Available: http://apps.who.int/iris/bitstream/10665/249155/1/9789241511216-eng.pdf?ua=1. Accessed: 1 October 2017.

10 Pagel C, Prost A, Hossen M, Azad K, Kuddus A, Roy SS. Is essential newborn care provided by institutions and after home births? Analysis of prospective data from community trials in rural South Asia. BMC Pregnancy Childbirth. 2014;14:99. Medline:24606612 doi:10.1186/1471-2393-14-99

11 Rahman M, Haque SE, Zahan S, Islam O. Noninstitutional births and newborn care practices among adolescent mothers in Bangladesh. J Obstet Gynecol Neonatal Nurs. 2011;40:262-73. Medline:21585526 doi:10.1111/j.1552-6909.2011.01240.x 
12 Kabwijamu L, Waiswa P, Kawooya V, Nalwadda CK, Okuga M, Nabiwemba EL. Newborn care practices among adolescent mothers in Hoima District, Western Uganda. PLoS One. 2016;11: e0166405. Medline:27855186 doi:10.1371/ journal.pone.0166405

13 Adejuyigbe EA, Bee MH, Amare Y, Omotara BA, Iganus RB, Manzi F, et al. "Why not bathe the baby today?": A qualitative study of thermal care beliefs and practices in four African sites. BMC Pediatr. 2015;15:156. Medline:26466994 doi:10.1186/s12887-015-0470-0

14 Moran AC, Choudhury N, Uz Zaman Khan N, Ahsan Karar Z, Wahed T, Faiz Rashid S, et al. Newborn care practices among slum dwellers in Dhaka, Bangladesh: a quantitative and qualitative exploratory study. BMC Pregnancy Childbirth. 2009;9:54. Medline:19919700 doi:10.1186/1471-2393-9-54

15 Sacks E, Moss WJ, Winch PJ, Thuma P, Van Dijk JH, Mullany LC. Skin, thermal and umbilical cord care practices for neonates in southern, rural Zambia: a qualitative study. BMC Pregnancy Childbirth. 2015;15:149. Medline:26177637 doi:10.1186/s12884-015-0584-2

16 Shamba D, Schellenberg J, Hildon ZJ, Mashasi I, Penfold S, Tanner M, et al. Thermal care for newborn babies in rural southern Tanzania: a mixed-method study of barriers, facilitators and potential for behaviour change. BMC Pregnancy Childbirth. 2014;14:267. Medline:25110173 doi:10.1186/1471-2393-14-267

17 World Health Organization. UNICEF. Joint Statement on home visits for the newborn child: a strategy to improve survival. Geneva: World Health Organization; 2009.

18 Stanton CK, Rawlins B, Drake M, Dos Anjos M, Cantor D, Chongo L, et al. Measuring coverage in MNCH: testing the validity of women's self-report of key maternal and newborn health interventions during the peripartum period in Mozambique. PLoS One. 2013;8:e60694. Medline:23667427 doi:10.1371/journal.pone.0060694 